\title{
Using Speed Cameras, Costs and Benefits and Driver Attitude
}

\author{
Hesam. Shabaniverki \\ Tarahan Parseh Transportation Research Institute, Tehran, Iran. \\ Email: hesam@shabaniverki.com
}

\author{
Leanne. Thomas, Monteiro Figueira, and Parsa Fallah Sheikhlari \\ Rensellaer Polytechnical Institute, USA; CEIT Consultant, Lisbon, Portugal; University of Heydarabad, India. \\ Emails: hesam@shabaniverki.com, thomasleanne8@hotmail.com, ceit-consult@oniduo.pt,p.fallah.sh@gmail.com
}

\begin{abstract}
Since the 1980 s, engineers tried to utilize intelligent transportation systems, ITS, as appropriate solutions to the basic problems of traffic management. ITS have been relied on to upgrade the safety level of transportation systems, to reduce the number and severity of accidents, and to improve the effectiveness of transportation methods. However, wide-spread implementation and deployment of these systems need to be behaviorally justified as well. Towards that goal, ITS must be integrated so as to model these systems for proper evaluation. This research is the study of the application of intelligent transportation systems in improving safety and driver behavior. A case study of the Tehran-Saveh Highway involving the deployment of ITS using speed control cameras for improving safety and the reduction of accidents was examined.
\end{abstract}

Index Terms - driver attitude, speed camera, its, cost and benefit, accident cost, accident reduction, safety analysis

\section{INTRODUCTION}

The most basic prerequisite for increasing the level of social welfare and development in any country is safe and smooth transportation. Consequently, one of the first symbols of the quality of life of in a country is its transportation systems. In many countries, transportation and traffic problems are major societal challenges which make a significant contribution to the national gross domestic product. Access to affordable, safe and efficient transportation for all citizens is one of the main policy considerations for any government.

Urban population centers in most countries are faced with many transportation and environmental problems. The problems include increased traffic, increased congestion on the roads, an increase in travel time and related costs, a reduced attractiveness of public transportation, as well as the environmental impact of transportation systems. In the 1960's, decision makers focused on the construction of streets, roads, and highways in order to reduce traffic problems. But the problems did not disappear completely, and transportation planners gradually became aware that the

Manuscript received January 1, 2014; revised March 26, 2014. potential for new capacity would be quickly swallowed up by consumers. Facilities also increased due to the need to invest a lot of time to run the overall systems. In order to overcome the above problems and limitations, traditional solution methods were typically employed.

With advances in communication technology and electronics in the latter half of the 1980s, the use of Intelligent Transportation Systems, ITS, were considered. Intelligent Transportation Systems are complex systems using automated tools and utilizing extensive planning to address traffic transportation problems. ITS provide enhanced safety, an increase in efficiency and productivity, and enhanced mobility and comfort. These features allow the passenger transportation systems to increase profitability, to increase the potential for future economic development, to reduce energy consumption and environmental costs caused by traffic congestion, and to progress in the area of development and implementation of ITS on roads. Therefore, road transportation authorities want to take advantage of ITS on their country's main roads.

A crucial factor in traffic accidents is the volume of deaths and injuries to humans, which impose high costs on society. During the fifty-eighth session of the United Nations General Assembly, it was revealed that approximately 1,300,000 people die each year in Iran at a cost equivalent to $\$ 518$ billion. ITS applications and research which rely on technology have been focused on urban areas. Safety problems in suburban areas are usually different from what can be seen within urban areas.

The following questions have often been raised and will be addressed by this study. Is ITS a solution to the problem of transportation systems or it is a reset point solution that can be used to handle transportation problems of current times that previously have been either partially or completely unsolvable?

Are the use of ITS effective in reducing accidents and increasing safety?

Due to the high volume of traffic on highways and freeways in Tehran, assuming priority over the interests of other benefits, the purpose of implementation of intelligent transportation systems in Iran is to reduce accidents. Reduction of accidents by the ITS, rather than 
providing other services, is an accepted principle. The cost-benefit method is used similarly to ITS in other parts of the world.

\section{LITERATURE REVIEW}

Cases of non-routine gains concerning ITS were examined by Eisele, Lomax \& Vadali in 2000. Potential positive influences on how land is used for transportation and the decision to use ITS are whether the raw materials and markets are available, and the increased chance of contact between public and private sectors. In 1993, Brand considered travel time reliability measures for ITS, such as the control of legal benefits, ease of installation and utilization, social acceptance, cooperation between agencies and make recommendations to improve data collection.

Zavrgyv, in 1996, suggested that other measures, such as reduction of new right-of-ways, improve the planning and management of transportation systems and improve job opportunities in the private sector. In fact, this criterion states that providing goods or services to people is a point worth making. It is noteworthy that the amount of money that a person pays to acquire goods or services reflects the full value of the goods or services based on what the individual believes. In other words, the demand for travel is composed of the cost required for managing a motor vehicle. While the estimated cost of the item used the first time is easy to estimate, each time a person is allowed to use the item makes the value difficult to determine [1].

Stamatiadis, Gartner, Winn \& Bond in 1998 and Lee in 1997 came to believe that the method of cost analysis which determines the benefits of the best systems is the most appropriate way to assess the benefits of ITS [2]. An appropriate framework for assessing the benefits and costs of ITS projects was presented by Chang in 1999. In his work, the benefits of the proposed framework for ITS have been classified by two different methods. The first method is based on the belief that the benefits of ITS can be categorized by the goals of ITS. There are five benefits gained by this approach: safety, mobility, system efficiency, productivity and environmental effects. The second method is based on the belief that the interests of the groups that receive the benefits can be classified. These groups are users, agencies and surrounding communities [3].

In 2006, a speed camera location finding project was done by the Transportation Institute in Iran based on the Analytic Hierarchy Process (AHP) method [3]. A speed cameras implementation guide was developed as a result of the project. In this project, speed cameras were modeled by a mathematical model. The results of this model determined the appropriate location of speed cameras according to the lowest cost and most benefits [4].

Implementation Strategy Formulation Project for ITS on Iran's roads was defined in 2007. This project aimed to determine the benefits, advantages and disadvantages of all aspects related to ITS [5]. The research that has been done in Iran to date has related mostly to the introduction and deployment of ITS and urban ITS. An article has been assessed about efficiency and benefits of ITS in roads.

\section{THE ROLE OF INTELLIGENT TRANSPORTATION SYSTEMS IN REDUCING ACCIDENTS}

This section examines the lives and economic losses caused by traffic accidents.

According to official statistics, the number of road fatalities that have occurred throughout the world has been estimated at 999,000 deaths in 1999, 1.1 million in 2002, 2.1 million in 2004 and more than 3.1 million deaths in 2009 [6]. More than 90\% of the world's road fatalities exist in developing countries. Middle Eastern countries are ranked high in road casualties, with Iran being one of the main countries with a high death rate on roads. The following diagram, Fig. 1, shows road fatalities for several different areas [7], [8].

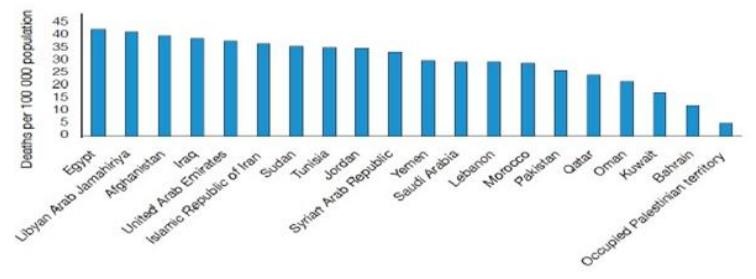

Figure 1. WHO report in 2010.

Fig. 2 depicts the results of efforts to control road accidents in different parts of the world. This diagram clearly shows that Middle Eastern countries have not only failed to reduce road accidents [8], but that the percentage of change in the number of accidents has steadily increased between 1987 and 1995.

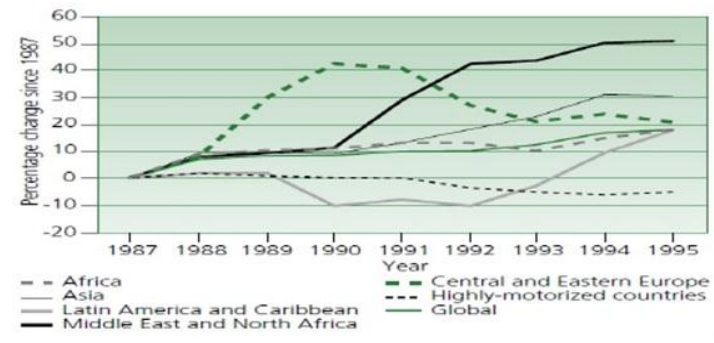

Figure 2. Process control to reduce road accidents in different parts of the world [8]

TABLE I. ITS IMPLEMENTED BY THE TEHRAN HIGHWAYS

\begin{tabular}{|c|c|c|}
\hline System Name & $\begin{array}{c}\text { Cost of } \\
\text { construction, } \\
\text { installation and } \\
\text { commissioning } \\
\text { (Million Rial) }\end{array}$ & $\begin{array}{c}\text { Annual } \\
\text { maintenance } \\
\text { costs (Millions } \\
\text { Rial) }\end{array}$ \\
\hline CCTV & 520 & 80 \\
\hline VMS & 435 & 77 \\
\hline Radio messages & 19500 & 4000 \\
\hline Traffic control center & 14300 & 600 \\
\hline Speed control cameras & 650 & 100 \\
\hline Center for Air Pollution Control & 9500 & 500 \\
\hline $\begin{array}{c}\text { Electronic Toll Collection } \\
\text { System }\end{array}$ & 32000 & 7000 \\
\hline
\end{tabular}


Intelligent transportation systems implemented by the Tehran highway is depicted in Table I. The table shows costs associated with the life of ITS.

\section{METHODOLOGY}

Modeling methodology to assess the technical and economical disposal of ITS to improve safety

In this study, due to the lack of information on the benefits of ITS, a breakeven analysis method is used. The benefits of the use of ITS and appropriate measures have been proposed using indices. The system is compared with the cost of its implementation. Economic evaluation in this study is evaluated by Microsoft Excel software. Consequently, the results can be used in ITS installation and can be assessed in the future.

The steps taken in the present study is displayed as follows:

Step 1: evaluation of transportation system objectives.

Step 2: At this step, an economic evaluation of the system and application installation is done after several years. The elapsed time of the project is calculated by determining the number of years since the beginning of the project until the year the analysis was performed.

Step 3: The benefits of using ITS were investigated. Indicators consistent with the purposes of the application of ITS were selected. For selection criteria, the existence of data before and after implementation of and compliance with the primary goal of ITS was essential to use. After the selection of indicators, the criterion to quantify the performance index was selected. It was estimated that the problem could be adapted to the system to determine how much money should be spent toward achieving the goal. Safety benefits were measured by counting the reduction in traffic accidents and in the severity of accidents.

Step 4: Costs resulting from the application of the ITS were determined. In this step, the costs of implementing ITS are quantified. These costs include the costs of implementation and the cost of installation and maintenance.

Step 5: The costs and benefits of using ITS were compared and the break-even point was estimated. At this stage of implementation, system maintenance costs are estimated, including interest charges.

Step 6: The final evaluation of ITS is conducted.

This phase is associated with engineering judgment. If it can be predicted that the use of ITS can bring benefits, execution of a system is recommended.

Due to the high volume of traffic on highways and freeways in Tehran, assuming priority over the interests of other benefits, the purpose of implementation of intelligent transportation systems in Iran is to reduce accidents. Reduction of accidents by the ITS, rather than providing other services, is an accepted principle. The cost-benefit method is used similarly to ITS in other parts of the world.

\section{RESULTS}

Of the systems mentioned, only Speed Control Cameras and Variable Message Signs are safety related. In most of the freeways, speed cameras have been used. Installation of Project Freeway Speed Cameras Tehran Saveh has been executed. Thus, the models for analysis of traffic before and after data for the speed control cameras are sufficient.

Tehran-Saveh Freeway accident data between 2009 and 2011 were examined. With regard to the number of accidents in which the vehicle is involved in a high-speed crash, it can be determined that 80 percent of all traffic accidents involved speeding.

TABLE II. ACCIDENTS ON THE TEHRAN-SAVEH HigHWAY IN THE FIRST 6 MONTHS OF 2009

\begin{tabular}{|c|c|c|c|c|c|}
\hline \multicolumn{2}{|c|}{ Death Accident } & \multicolumn{2}{|c|}{ Injury Accident } & \multirow{2}{*}{ Other } & Total \\
\cline { 1 - 4 } Number & $\begin{array}{c}\text { Death } \\
\text { number }\end{array}$ & Number & Injuries & & \\
\hline 26 & 27 & 1984 & 2469 & 13921 & 15931 \\
\hline
\end{tabular}

TABLE III. ACCIDENTS ON THE TEHRAN-SAVEH HighwAY IN THE FIRST 6 MONTHS OF 2011

\begin{tabular}{|c|c|c|c|c|c|}
\hline \multicolumn{2}{|c|}{ Death Accident } & \multicolumn{2}{|c|}{ Injury Accident } & \multirow{2}{*}{ Other } & Total \\
\cline { 1 - 4 } Number & $\begin{array}{c}\text { Death } \\
\text { number }\end{array}$ & Number & Injuries & & \\
\hline 21 & 23 & 1926 & 2163 & 8628 & 10575 \\
\hline
\end{tabular}

TABLE IV. Decrease In ACCIDENTS ON THE TeHRAN SAVEH HIGHWAY IN 6 MONTHS, COMPARISON BETWEEN 2009 AND 2011

\begin{tabular}{|c|c|c|c|c|c|}
\hline \multicolumn{2}{|c|}{ Death Accident } & \multicolumn{2}{|c|}{ Injury Accident } & \multirow{2}{*}{ Other } & Total \\
\cline { 1 - 4 } Number & $\begin{array}{c}\text { Death } \\
\text { number }\end{array}$ & Number & Injuries & & \\
\hline 5 & 4 & 58 & 306 & 5293 & 5356 \\
\hline
\end{tabular}

The cost of each item and the total cost of accidents declined in Tehran-Saveh.

The cost of each item and the total cost of accidents in Tehran-Saveh fallen in Table V is displayed.

TABLE V. COST OF ITEMS AND THE TOTAL COST OF ACCIDENTS IN TEHRAN-SAVEH

\begin{tabular}{|c|c|c|}
\hline Cost Type & Millions Rials & Percent \\
\hline $\begin{array}{c}\text { The cost of treating the } \\
\text { injured }\end{array}$ & 19160 & 4.16 \\
\hline Lost time injuries & 593 & 0.13 \\
\hline $\begin{array}{c}\text { Potential economic value } \\
\text { of the work of temporary } \\
\text { disability }\end{array}$ & 822 & 0.18 \\
\hline $\begin{array}{c}\text { The economic value of } \\
\text { time wasted for those } \\
\text { who are indirectly } \\
\text { involved in the accident. }\end{array}$ & 3875 & 0.84 \\
\hline $\begin{array}{c}\text { The cost of those killed, } \\
\text { permanent disability, } \\
\text { Sadness, grief, mental } \\
\text { wounds }\end{array}$ & 109390 & 23.77 \\
\hline $\begin{array}{c}\text { The cost of machinery } \\
\text { and equipment damaged } \\
\text { or destroyed }\end{array}$ & 295353 & 64.19 \\
\hline Administrative costs & 30963 & 6.73 \\
\hline Total & 460156 & 100 \\
\hline
\end{tabular}

Due to the reduction of accidents according to statistics using Speed cameras are only concerned organizations.

The module costs, the total cost of installation and system maintenance are estimated at 90 years. Cameras 
are installed by "Goth So" company. Speed camera mounting device 16 according to the cost of installing these systems is equivalent to 12,000 Million Rials.

Given the high correlation between the projects economically feasible should be equal to 1 ratio of benefits to costs.

The ratio of benefits to costs assumed equal to one.

\section{$\mathrm{B} / \mathrm{C}=1$}

Thus, for the ratio of benefits to costs is equivalent to a $2.6 \%$ reduced crash costs.

\section{$\mathrm{B} / \mathrm{C} \sim 2.6 \%$}

For speed cameras installation costs, if the cameras can decrease $2.6 \%$ accident cost in the first year of installation it will be economically feasible. Fig. 3 shows the breakeven analysis to demonstrate safety.

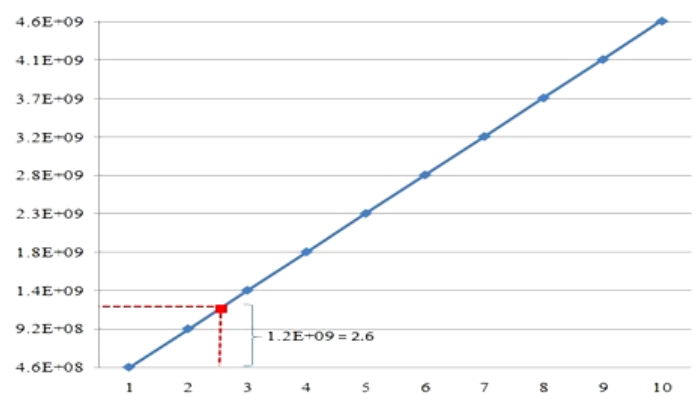

Figure 3. Speed cameras feasibility

According to the graph, if the accidents decrease about 2.6 percents, the benefits of speed cameras will be equal to 1200000000 Rials. This is the 1 ratio point.

According to accident statistics, car accident in 2009 compared with 2011 for a crash to reduce the rate of fatal crashes by $15 \%, 13 \%$ injuries accidents and damage is estimated at $38 \%$.

Rates of return on capital of $10 \%$ are assumed. Percent of the accident reduction rate that is needed to equalize costs and benefits for the first decade is shown in the below graph.

According to the charts after six years, the economic justification for installing cameras to reduce accidents required to be less than $1 \%$.

After 6 years accidentally dropped charges (benefits) is so large we need to decrease the accident rate of less than $1 \%$ interest, the cost is more economical design.

High speed vehicles are a major cause of accidents. Implementation and installation of speed cameras can increase the safety of passing vehicles. The use of speed cameras caused a decrease in the number of accidents on this Iranian highway.

If the highway or freeways in urban, high-speed vehicles are a major cause of accidents, construction and installation of speed cameras are passing vehicles can increase safety levels. Based on the analysis of each part of the interest earned until the interest costs of the proposed system is equal to one. For years and years the project has been to the future.

As shown, the death volume decreased by 15 percent in 2011. The ratio of injuries decreased 12.4 percent.
Accidents that caused car crashes decreased 38.02 percent; equaling 5293 accidents. With speed cameras, the number of high speed driving decreased from 13000 in 2009 to only 3000 in 2011 . In conclusion, the safety index definitely improved by using speed cameras.

\section{SUGGESTION}

Recommended to improve safety and reduce accidents, freeway traffic areas and highways in metropolitan ITSs (highway entrance ramp control systems, etc.), especially speed cameras are equipped. In the field, education and culture, suitable for traffic laws is highly effective in reducing accidents.

Analysis of the mathematical model requires robust statistical base. How to record accidents in the proper statistics and reliability at very low figures released by the state police will cause very high percentage of error in similar research. Therefore, it is recommended that a system be developed to replace the old system of police.

As future research, this comprehensive and practical achievement of the index parameters of interest in various fields of ITSs in Tehran freeways is recommended.

Study on the benefits and costs of ITSs are proposed. Hidden costs (indirect) and infrastructure (Technology ITS) and modeled on the maximum number of speed cameras in a way that is economical in terms of maximum coverage is recommended.

\section{CONCLUSION}

Crucial factors in traffic accidents and deaths as well as injuries are conspicuous. They impose large costs on society. A report of the Fifty-eighth session of the UN General Assembly shows that 1300000 people dead in a year (equivalent to cost 518 billion).

Deaths in accidents, is one of the most important type of human mortality in Iran. The age group is from 5 to 25 years. $25 \%$ mortality in this age group is due to accidents.

Our country in recent years to become one of the foci of the recent World Bank studies formally traffic safety situation in Iran "crisis" is known. Despite this situation, the economic aspects of traffic safety-related crashes cost the nation more specifically, suburban, has received little attention. One of the most important factors that it has effective influence on intensity and number of accidents is human factor. Using speed cameras will focus on making it improved by enforcement. So the investment in road safety with speed cameras approach is of great importance.

In this study, the existing models for economic evaluation of intelligent transport systems in the world, has been studied. Reduced accidents and costs of accidents in Tehran-Saveh highway is presented. Results are showing that using speed cameras has great effect on drivers in Iran and it has so many advantages in longtime as well.

In this model of benefits - costs for economic evaluation of ITSs are used. Costs and benefits of using this system is specified and the value of the monetary unit is turned on. The economic evaluation is performed by 
comparing costs and benefits. Analysis of each component of interest expense for the benefit of the proposed system is obtained.

\section{ACKNOWLEDGEMENT}

The authors would like to acknowledge Mr. Amir Hassanabadi from Iran for providing data and sharing the thesis for this paper.

\section{REFERENCES}

[1] A. Hassanabadi, "Development of tech-economical model for analysis of using its to improve road safety," Highway and Transportation Dept, Islamic Azad University of Tehran, Science and Research Branch, Tehran, 2013.

[2] D. Gillen, "Caltrans TOPS evaluation: Assessing the net benefits of ITS applications," University of California, Berkeley, 2001, pp. 12-20.

[3] E. Bekiaris and Y. J. Nakanishi, "Economic impacts of intelligent transportation systems: Innovations and case studies," in Research in Transportation Economics, Elsevier, E. Bekiaris and Y. J. Nakanishi, Eds., vol. 8, 2004, ch. 2.

[4] Federal Highway Administration, Benefits and Costs of Full and ITS Deployment Seattle, 2003, ch. 2. pp .3.

[5] ITS America, "ITS America's 2009-2010 Annual Report," ch 3, 2010, pp. 9-14.

[6] M. Paradowska, "Intelligent transport systems as an instrument for sustainable urban development," in Economic and Environmental Studies, vol. 11, no. 4, 2011, pp. 11-14.

[7] Data System, A Road Safety Manual, World Health Organization, 2010.

[8] World Health Organization Library Cataloguing-in-Publication Data, "World report on road traffic injury prevention - summary," Switzerland Geneva, 2004, ch .4.

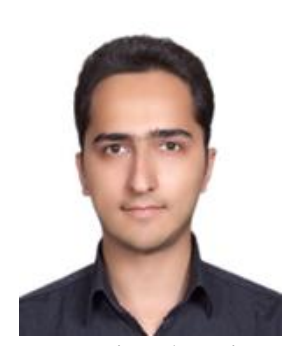

Prof. Eng. Hesam Shabaniverki was born in Qazvin, Iran in 1985. He received his MSc in Highway and Transportation Planning and Engineering from Islamic Azad University of Tehran Science and Research Branch, Tehran, Iran, in 2013. $\mathrm{He}$ received his B.S. in CivilEngineering, Imam Khomeini International University, Qazvin, Iran, 2009 and High School Diploma in Mathematics and Physics, Shahid Babaee High School, Exceptional Talents School Organization, Qazvin, Iran, 2003. He is working as a traffic consultant in Asia and Europe and he is a professor in Qazvin Municipality University. Now he is Research Associate in Tarahan Parseh Transportation
Institute and Associate Professor in Qazvin Municipality University.

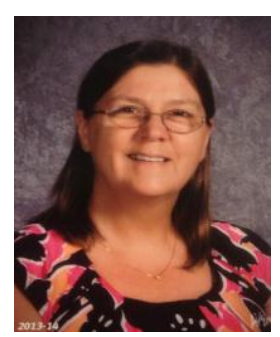

Leanne Thomas was born in Milwaukee, Wisconsin. She earned a Bachelor of Science Degree in Medical Technology from the University of Wisconsin Milwaukee, a Master of Science Degree from Rensellaer Polytechnical Institute in Troy, New York, and a Master of Education Degree from George Mason University in Fairfax, Virginia. She is currently a National Board Certified Teacher as well as a SMART Master Teacher.

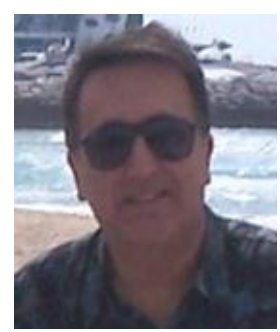

Prof. Monteiro Figueira is since 1990 the General Director of CEIT Consultores. Engenheiros em Infraestruturas de Transportes, a Portuguese consulting firm focusing on transportation, parking, mobility, traffic enginee ring and roadways and Senior Professor at the Universidade Lusofona (ULHT) in Lisbon.

Prof. Monteiro Figueira consults on many projects regarding mobility and transportation in Portugal, Angola, Mozambique and Macao and is the author of books and articles on highway design and transportation planning. He is currently involved in different projects in Africa (Angola and Mozambique) for governmental departments.

Prof. Monteiro Figueira worked at JAE - Official National Board of Highways in Portugal for thirty years and was a representative of Portugal at the European Commission in Brussels, at DG VII.

He was a Professor for more than twenty years at the Technical University in Lisbon until 2000 and at Military Academy, until 1999.

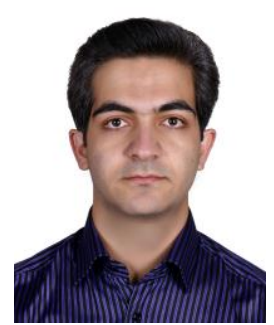

Parsa Fallah Sheikhlari was born in Qazvin, Iran in 1984.

MBA from Jawaharlal Nehru university of Hyderabad, India in 2011. He received his B.S. in IndustrialEngineering, Buali-Sina University, Hamedan, Iran,2009 and High School Diploma in Mathematics and Physics, Shahid Babaee High School, Exceptional Talents School Organization, Qazvin, Iran, 2003. He is working as Industrial Consultant. 